\title{
Selective Non-Catalytic Reduction for Nitrogen Dioxides Reduction in Preheater Lime Kilns
}

\author{
Gideon M. Siringi \\ Lhoist North America \\ 5600 Clearfork Main St. \\ Fort Worth, TX, 76109, USA
}

\begin{abstract}
Nitrogen dioxide emissions commonly referred to as NOx from industrial plants is becoming a worldwide issue due to the impact on the environment and as governmental regulations become more stringent, it has become necessary to apply known emission mitigation technologies from one industry to another. One such technology which has been widely successful in coal-fired boilers for power plants is Selective Non-Catalytic Reduction (SNCR).In this paper, findings on the application of SNCR in preheater lime kilns are discussed. The main challenge for preheater lime kilns is finding a suitable location for injection of the reagent for the SNCR reaction. An SNCR trial in two preheater lime kilns sought to find out if SNCR technology can be applicable in the lime industry, how much NOx reduction can be achieved, which of the two reagents, urea and ammonia, would give better NOx reduction efficiency, the ideal location for injection and the best nozzle configuration. A reduction of 50-60\% in NOx was achieved making SNCR technology an economically viable alternative for NOx reduction. Both urea and ammonia were found to be effective reagents for SNCR, but urea was more effective and therefore recommended for use. The ideal location was identified as the preheater cone with four nozzle configuration. No side effects like ammonia slip and loss of production was noted. Increase in specific heat consumption was negligible. Presence of carbon monoxide above 5000 ppm was found to reduce SNCR effectiveness by about 10\% and therefore running SNCR in oxidized conditions is recommended.
\end{abstract}

Keywords: SNCR, Nitrogen Dioxides Emissions, Lime Kilns, NOx Emissions, Urea injection for NOx Control, Ammonia injection for NOx control, Emissions Control in Lime kilns, Emissions Best Available Technology.

\section{Introduction}

Nitrogen oxides (NOx) represent a family of seven compounds though the Environmental Protection Agency regulates only nitrogen dioxide $\left(\mathrm{NO}_{2}\right)$ as a surrogate for this family of compounds because it is the most prevalent form of NOx in the atmosphere that is generated by human activities (Clean Air Technology Center (MD-12), 1999). $\mathrm{NO}_{2}$ is not only an important air pollutant by itself, but also reacts in the atmosphere to form ozone $\left(\mathrm{O}_{3}\right)$ and acid rain (Clean Air Technology Center (MD-12), 1999).

NOx emission is becoming a worldwide issue due to the impact on environment and as governmental regulations on gaseous emissions from industrial plants become more stringent, it has become necessary to apply known emission mitigation technologies from one industry to another. One such technology which has been widely used successfully in coal-fired boilers for power plants is Selective Non-catalytic Reduction (SNCR) to control NOx but has not been very successful on its own in the preheater lime kilns (United States Environmental Protection Agency, 2002). The main challenge for preheater lime kilns is finding a suitable location for injection of either urea or ammonia for the SNCR reaction.

As noted in Figure 1, the injection location has to be between the kiln exit (Point \#3) and the preheater inlet (Point \#4) though in this section the temperatures can be higher than $2000^{\circ} \mathrm{F}\left(1100^{\circ} \mathrm{C}\right)$ which is above the suitable temperature range for SNCR Reaction. In SNCR ammonia or urea should be injected in a region where temperature is between $1600-2000^{\circ} \mathrm{F}\left(900-1100^{\circ} \mathrm{C}\right)($ Clean Air Technology Center (MD-12), 1999). At lower temperatures, the reaction does not take place and the injected urea or ammonia escapes unreacted through the stack (ammonia slip). At higher temperatures, the injected ammonia or urea is broken down to form more NOx. Lowering the kiln exit temperatures would compromise kiln output.

Selective Catalytic Reduction (SCR) which uses a catalyst to enhance the reaction between either urea or ammonia and NOx is not an option for lime kilns as the catalyst requires that exhaust gas have no more than $0.5 \%$ oxygen (Clean Air Technology Center (MD-12), 1999) and some catalyst manufactures specify sulfur dioxide $\left(\mathrm{SO}_{2}\right)$ in the exhaust gases be less than $20 \mathrm{ppm}$ both of which are not practical for lime kilns especially those that burn high sulfur fuels like petroleum coke. 
Selective Non-Catalytic Reduction (SNCR) is a post-combustion control technology based on the chemical reduction of nitrogen oxides (NOx) into molecular nitrogen $\left(\mathrm{N}_{2}\right)$ and water vapor $\left(\mathrm{H}_{2} \mathrm{O}\right)$ by injection of either urea $\left(\mathrm{CO}\left(\mathrm{NH}_{2}\right)_{2}\right.$ or ammonia $\left(\mathrm{NH}_{3}\right)$ solution. This technology is based on temperature ionizing the ammonia or urea instead of using a catalyst or non-thermal plasma. NOx is represented as Nitric Oxide (NO) since it is the predominant form of NOx within the combustion chamber (United States Environmental Protection Agency, 2002)

$2 \mathrm{NO}+2 \mathrm{NH}_{3}+\frac{1}{2} \mathrm{O}_{2} \rightarrow 2 \mathrm{~N}_{2}+3 \mathrm{H}_{2} \mathrm{O} \quad$ Equation 1

$2 \mathrm{NO}+\mathrm{CO}\left(\mathrm{NH}_{2}\right)_{2}+\frac{1}{2} \mathrm{O}_{2} \rightarrow 2 \mathrm{~N}_{2}+\mathrm{CO}_{2}+2 \mathrm{H}_{2} \mathrm{O} \quad$ Equation 2

Nitrogen oxides (NOx) pollutants are primarily formed through combustion process. While flue gas is within the combustion unit, about $95 \%$ of the NOx exists in the form of nitric oxide (NO)(United States Environmental Protection Agency, 2002). The balance is nitrogen dioxide $\left(\mathrm{NO}_{2}\right)$, which is unstable at high temperatures. Once the flue gas is emitted into the atmosphere, most of the $\mathrm{NO}$ is ultimately converted to $\mathrm{NO}_{2}$. $\mathrm{NOx}$ in the atmosphere reacts in the presence of sunlight to form ozone (O3)(Clean Air Technology Center (MD-12), 1999).

NOx is generated in one of three forms; Fuel NOx, Thermal NOx, and Prompt NOx(United States Environmental Protection Agency, 2002). Fuel NOx is produced by oxidation of nitrogen in the fuel source at temperatures ranging from $850-950^{\circ} \mathrm{C}\left(1560-1740^{\circ} \mathrm{F}\right)$ (Lafarge Cement- Techinical Agenda, 2005). Combustion of fuels with high nitrogen content such as coal and residual oils produces greater amounts of NOx than those with low nitrogen content such as distillate oil and natural gas. Thermal NOx is formed by the fixation of molecular nitrogen and oxygen at temperatures greater than $3600^{\circ} \mathrm{F}\left(2000^{\circ} \mathrm{C}\right)($ United States Environmental Protection Agency, 2002) though formation starts at temperature above $1200^{\circ} \mathrm{C}\left(2200^{\circ} \mathrm{F}\right)$ (Lafarge Cement- Techinical Agenda, 2005). Formation rate for thermal NOx is affected by temperature and oxygen concentration. Prompt NOx forms from the oxidation of hydrocarbon radicals near the combustion flame and produces an insignificant amount of NOx. The significant amount of NOx in the lime kiln is thermal NOx which is formed in the kiln burning zone (Point \#2 in Figure 1).

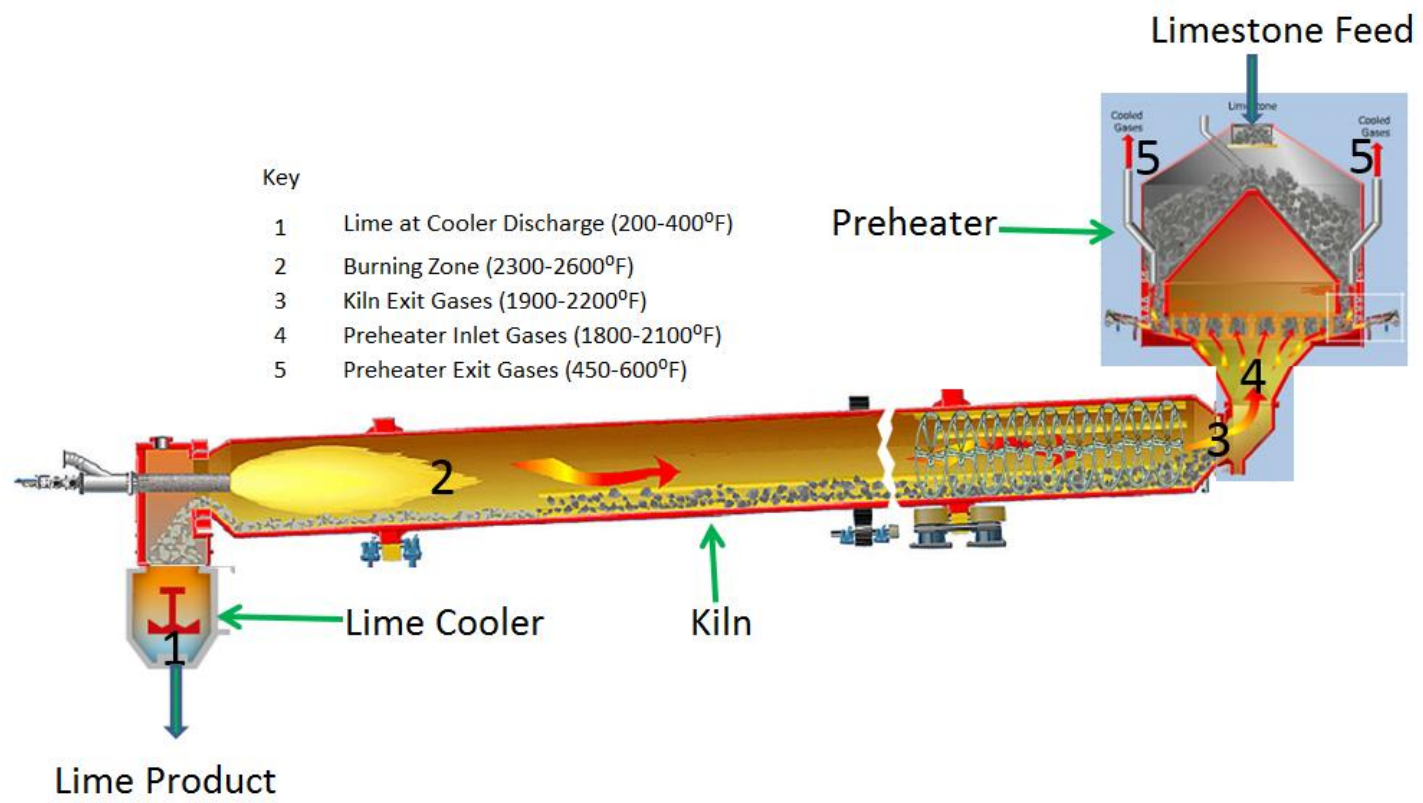

Figure 1: Preheater Lime Kiln Schematic

\section{Experimental Set-Up}

\section{Test Set-up}

The SNCR test was conducted on 800 tons of lime per day kiln and again on a 1000 tons of lime per day kiln. For each kiln, the test involved changing reagents (urea and ammonia), varying the flow rates of each reagent (0-3.5 gallons per minute), changing the number of injection nozzles (2,3 or 4) and changing location of injection (transfer chute, preheater cone and preheater roof) as shown in Figure 2.The reagents used for the test was 19\% ammonia and 32.5\% urea solutions. 
The ammonia and urea solutions were delivered to the test site in totes from which the solutions were pumped from during the test. Figure 3 shows the general arrangement of the testing rig system. A hose was connected from the outlet of the totes to the inlet side of the pump. The flow rate was controlled by a manual valve located in the return branch of the rig which takes any solution not pumped to the nozzles back to the top of the totes to be reused. A second valve located before the flow meter was used to control the pressure before the flowmeter. The flowmeter was in the branch that supplies the nozzles with the reagent. Following the flowmeter is another valve which remained fully open while in operation.

The reagent solution was pumped into the nozzle manifold at the given injection point which allowed up to four injectors to be used at the same time. Each of the four branches was equipped with a manual ball valve. Tubing connected the manifold to each of the injectors in use. Another set of tubing connected each injector to a separate manifold which was supplied with compressed air. The compressed air was used to atomize the reagent and spread it into the duct to provide more reaction surface area and to cover more of the cross-sectional area of the duct. The air pressure was typically between 30-60 PSIG.

The nozzles were placed in the ductwork at one of the predetermined locations which Included Transfer Chute, Preheater Cone and Preheater Roof as shown in Figure 2.

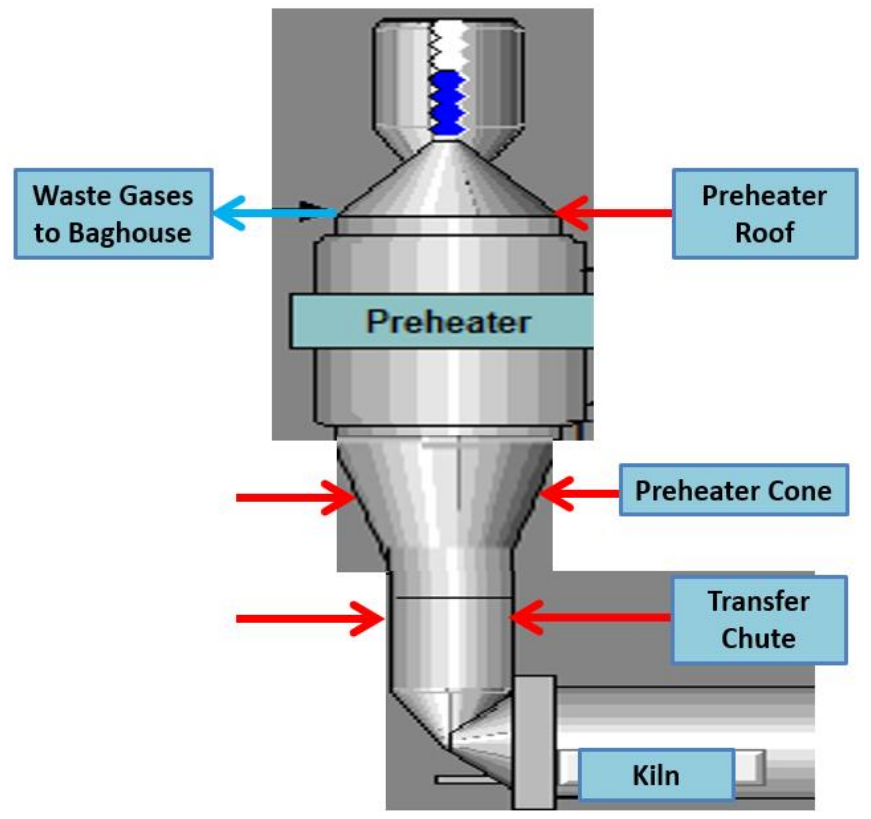

Figure 2: Lime Kiln Preheater Schematic showing Injection Locations

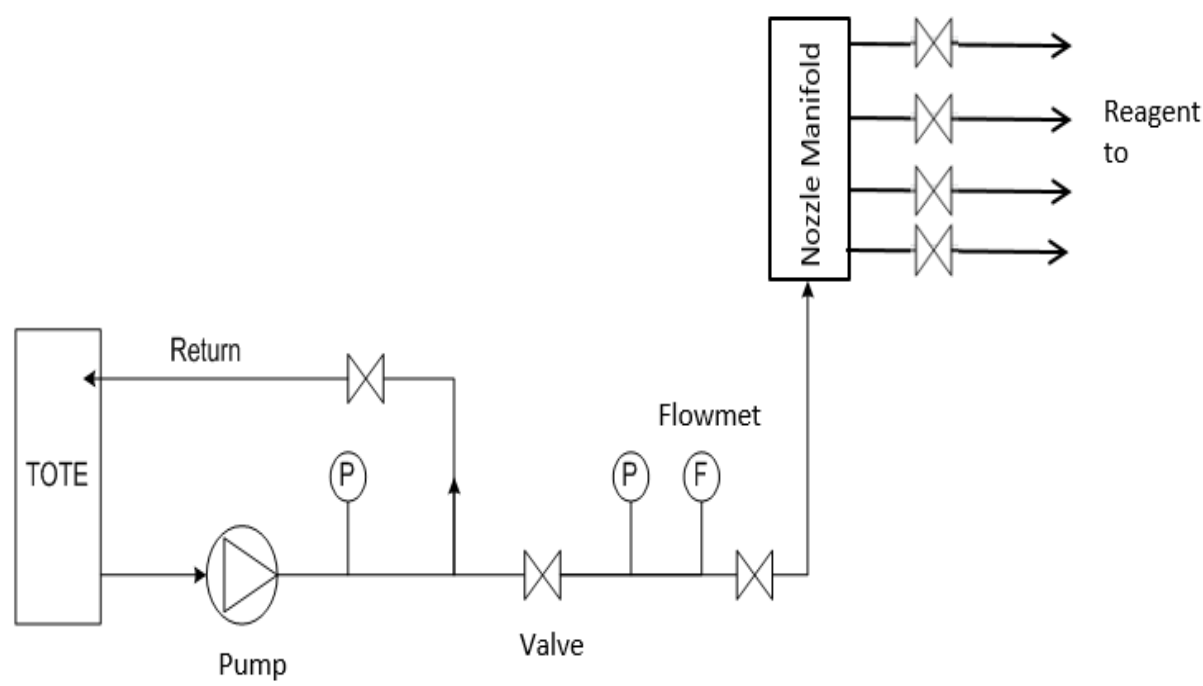

Figure 3: Test Rig Schematic 
Objectives of the test were:

* Find out if SNCR technology can be used for preheater lime kilns and how much NOx reduction can be achieved through the process.

* Find out which of the two reagents, urea and ammonia, would give better NOx reduction efficiency.

* Establish if SNCR can be an economically viable alternative for NOx reduction in preheater lime kilns.

* Find out the best location for injection of reagent in a preheater lime kiln

* Find out the best Nozzle configuration that would give the best efficiency.

\section{Test Procedure}

i. In order to test the reduction capability for each solution, following a baseline period in which emissions are monitored, the pump was turned on, and the flow was adjusted to a pre-determined flow rate in gallons per minute (gpm). The following flow rates were initially used $1 \mathrm{gpm}, 2 \mathrm{gpm}, 3 \mathrm{gpm}$ and $3.5 \mathrm{gpm}$. Following approximately 30 minutes of operation of the pump at this flow rate, the pump was stopped, and the system was allowed to come to equilibrium. The NOx reduction was calculated from the steady-state emission during the pump running period and the average of the baseline periods before and after the injection period.

ii. Step (i) was repeated for each reagent (Urea and Ammonia) and for each location (transfer chute and preheater cone). Preheater roof did not perform as expected and the test was stopped once ammonia slip was noted.

iii. Nozzle configurations (number and location) and kiln conditions (reducing and oxidizing) was also varied and effect on performance on SNCR monitored.

iv. After parametric testing for each reagent and location, the best location and reagent was chosen. This reagent was then run at the location chosen by varying flow rates from 0-1.2 gpm at 0.2 increments. This testing was run for $8 \mathrm{hrs}$ a day for 4 days for each kiln.

\section{Data Collection}

i. Stack Gaseous and Emission data $\left(\mathrm{NOx}, \mathrm{SO}_{2}, \mathrm{CO}, \mathrm{O}_{2}, \mathrm{CO}_{2}\right)$ was collected as recorded by the plant Continuous Emission Monitoring System (CEMS)

ii. A continuous gas sampling system (MKS MultiGas 2030 FTIR) was set-up at a baghouse inlet to monitor ammonia slip levels before the potential for scrubbing of ammonia in the baghouse. The gas species collected from the MKS included NOx, $\mathrm{CO}, \mathrm{NH}_{3}, \mathrm{~N}_{2} \mathrm{O}, \mathrm{CO}_{2}, \mathrm{H}_{2} \mathrm{O}, \mathrm{H}_{2} \mathrm{SO}_{4}, \mathrm{HCl}, \mathrm{SO}_{2}, \mathrm{CH}_{4}, \mathrm{C}_{3} \mathrm{H}_{8}$, and formaldehyde. The MKS reported emissions on a wet basis. Operational and calibration maintenance checks were made daily on each equipment to ensure proper reporting. A second analyzer monitored $\mathrm{O}_{2}$ continuously at the baghouse inlet.

\section{Definitions}

Baseline NOx would alternatively be referred to as Uncontrolled NOx while NOx level during urea or ammonia injection would be referred to as Controlled NOx. The data used in the analysis is from the Continuous Emission Monitoring System (CEMS).

The Normalized Stoichiometric Ratio, NSR, indicates the actual amount of reagent needed to achieve the targeted NOx reduction. The actual quantity of reagent is greater than the theoretical quantity due to reaction kinetics. The NSR is defined as:

NSR $=\frac{\text { Moles of equivalent } \mathrm{NH}_{3} \text { Injected }}{\text { Moles of Uncontrolled } \mathrm{NO}_{x}}$ Equation 3

Reagent utilization is the ratio of moles of reagent reacted to the moles injected. This indicates how much reagent is being reacted versus how much reagent is passing through as ammonia slip or converted to other byproducts e.g. $\mathrm{N}_{2} \mathrm{O}$. Utilization of reagent is calculated from the NSR and the NOx reduction efficiency as follows:

Utilization $=\frac{N O_{x} \text { Reduction Ef ficiency }}{N S R} \quad$ Equation 4

Baseline NOx

Baseline NOx $=\frac{\text { Average NOx Before Injection }+ \text { Average NOx after Injection }}{2}$ Equation 5

NOx Reduction Efficiency

Nox Reduction Efficiency $=\frac{\text { Baseline NOx }- \text { Average NOx During Urea Injection }}{\text { Baseline NOx }} \times 100$ Equation $\epsilon$

\section{Experimental Results}

Urea vs Ammonia 
It was found that both reagents (urea and ammonia) performed well in terms of reducing NOx in the gas stream. Ammonia reduction efficiency was up to $50 \%$ while urea was able to reduce NOx by up to $60 \%$ (Figure 4). It is believed that urea performed well compared to ammonia due to the temperature range in the injection region being more favorable to urea.

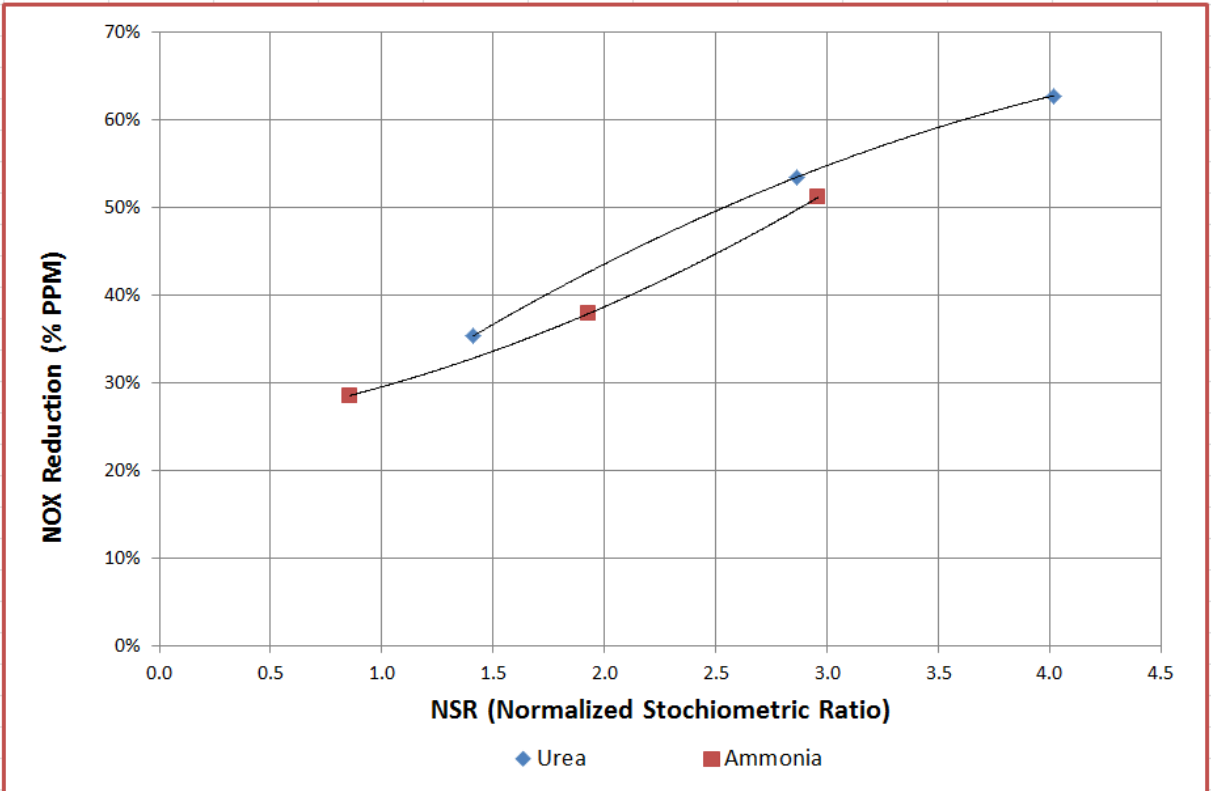

Figure 4: Comparison between Urea and Ammonia as reagents

The temperature in injection regions (transfer chute and preheater cone) ranged from $1900-2200^{\circ} \mathrm{F}$ during the testing. Optimum SNCR temperature for ammonia is in $1600-1900^{\circ} \mathrm{F}\left(871-1038^{\circ} \mathrm{C}\right)$ range; with peak removal typically occurring at $1750^{\circ} \mathrm{F}\left(954^{\circ} \mathrm{C}\right)$ while optimum SNCR temperature for urea in $1700-2000^{\circ} \mathrm{F}\left(927-1093^{\circ} \mathrm{C}\right)$ range; with peak removal typically occurring at $1850^{\circ} \mathrm{F}\left(1010^{\circ} \mathrm{C}\right)$ (EPRI, 2004)(Sun, 2005).

As shown in Figure 5, urea performed better both at the preheater cone and transfer chute in terms of lower consumption for equal NOx reduction and the maximum NOx reduction that can be achieved. Urea was recommended due to better NOx reduction efficiency and also being easy and safe to handle compared to ammonia. At room temperature, urea is normally a liquid while ammonia is a gas. Ammonia is normally delivered in compressed form as a clear, colorless liquid. Ammonia gas is a colorless highly irritating gas with a sharp suffocating odor. When ammonia enters the body as a result of breathing, swallowing or skin contact, it reacts with water to produce ammonium hydroxide. This chemical is very corrosive and damages cells in the body on contact.

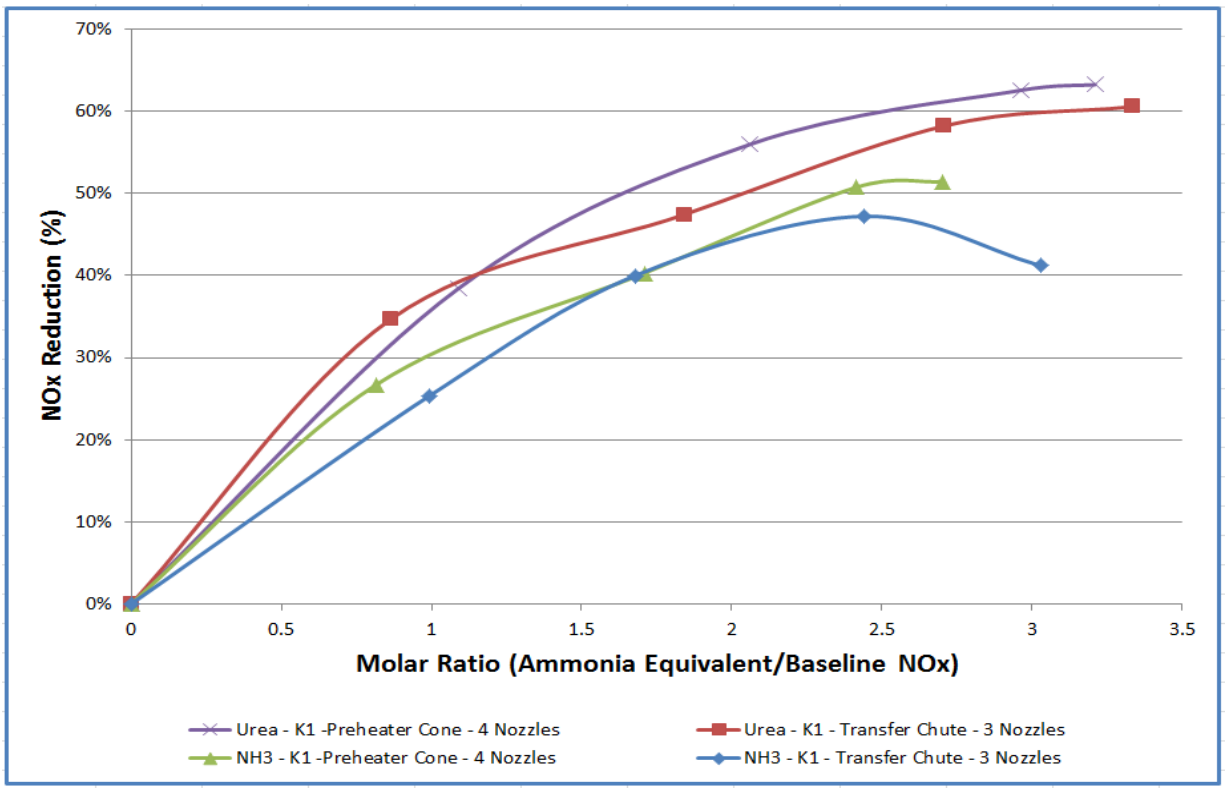

Figure 5: Comparison between reagents urea and ammonia 


\section{Number of Nozzles}

Using more nozzles improved the reduction efficiency as shown in Figure 6.The number of nozzles were increased from two to three and then four. Increasing the number of nozzles increases the degree of mixing which improves the dispersion of the reagent in the flue gas.

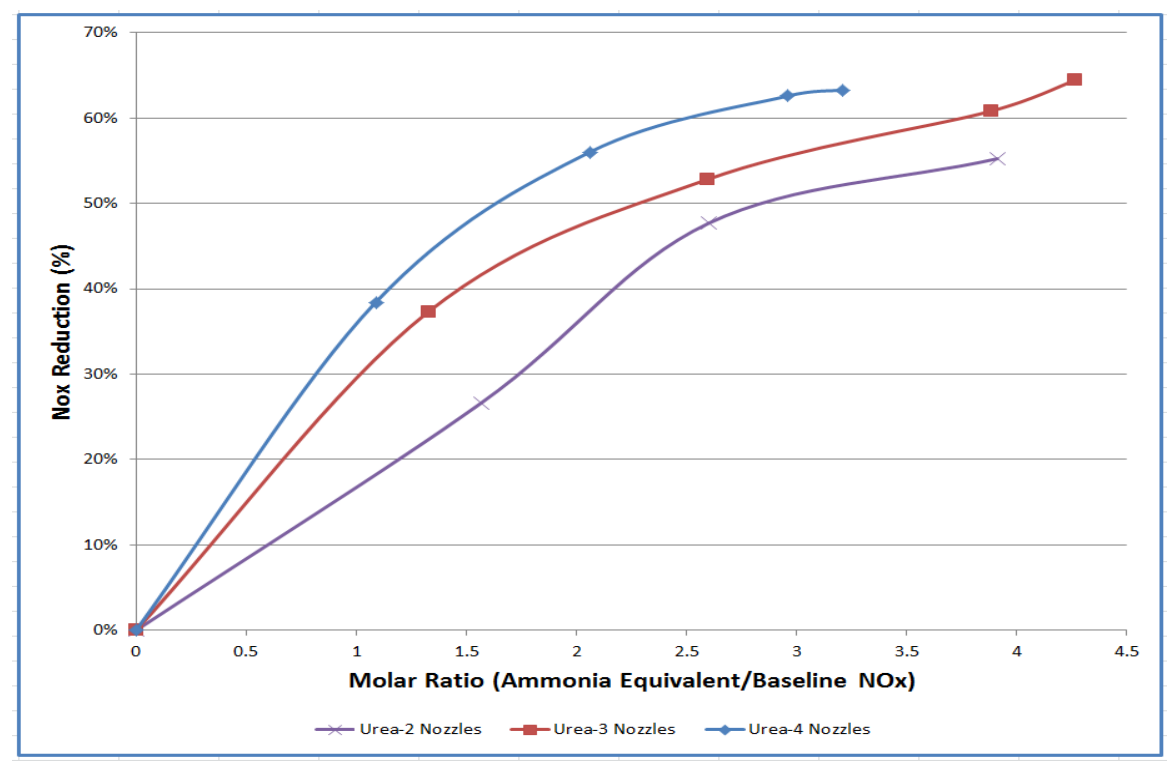

Figure 6: Comparison of number of nozzles against NOx reduction

The dispersion of the reagent must occur rapidly since the residence time for the flue gas in the optimal temperature range for the reaction is in the order of milliseconds. To improve the reagent dispersion and mixing in the flue gas, compressed air was also injected with the reagents to ensure maximum atomization. The injectors (nozzles) were arranged in such a way to control the spray angle and direction of the injected reagent to cover maximum flow area. Based on the observations, it was recommended to use four injectors to maximize on NOx reduction.

\section{Injection Location}

Three locations were used as injection points for the two reagents- urea and ammonia. The three locations were in the transfer chute, preheater cone and preheater roof (Refer to Figure 2).

From Figure 7and Figure 8 it is clear that the best location for higher NOx reduction is the preheater cone irrespective of which reagent is used. Higher reduction efficiency was achieved for this location and lower amounts of reagent used for the same NOx reduction.

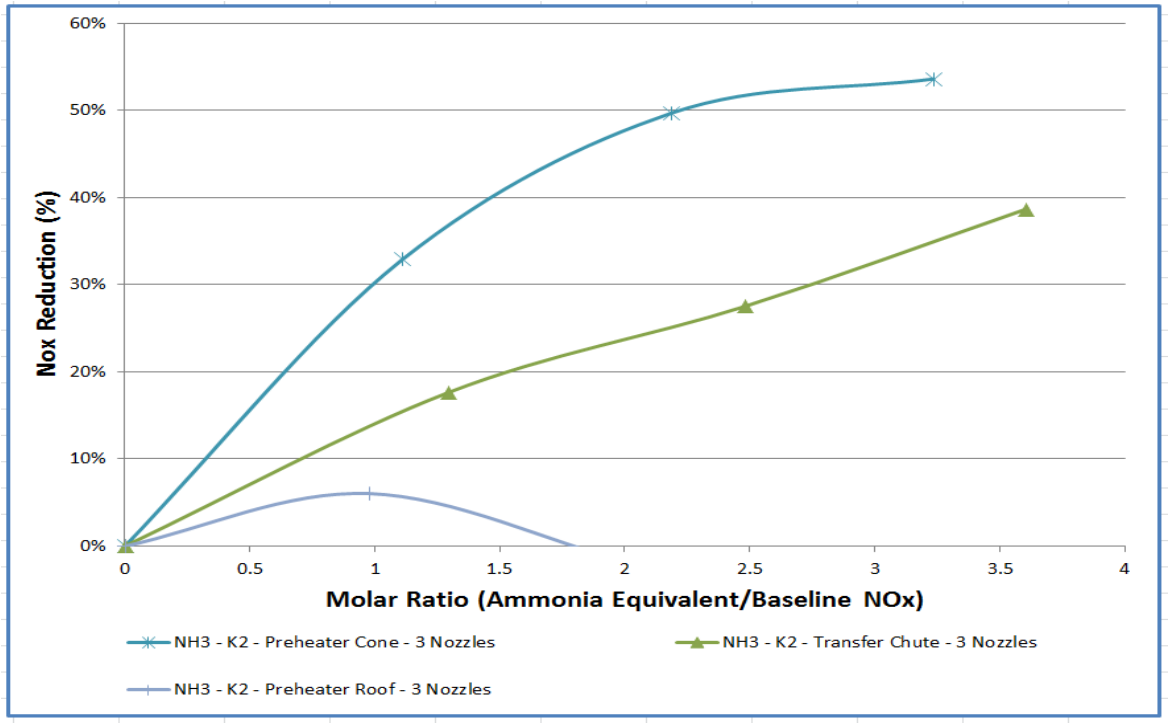

Figure 7: Comparison of Injection Locations for Ammonia Reagent 


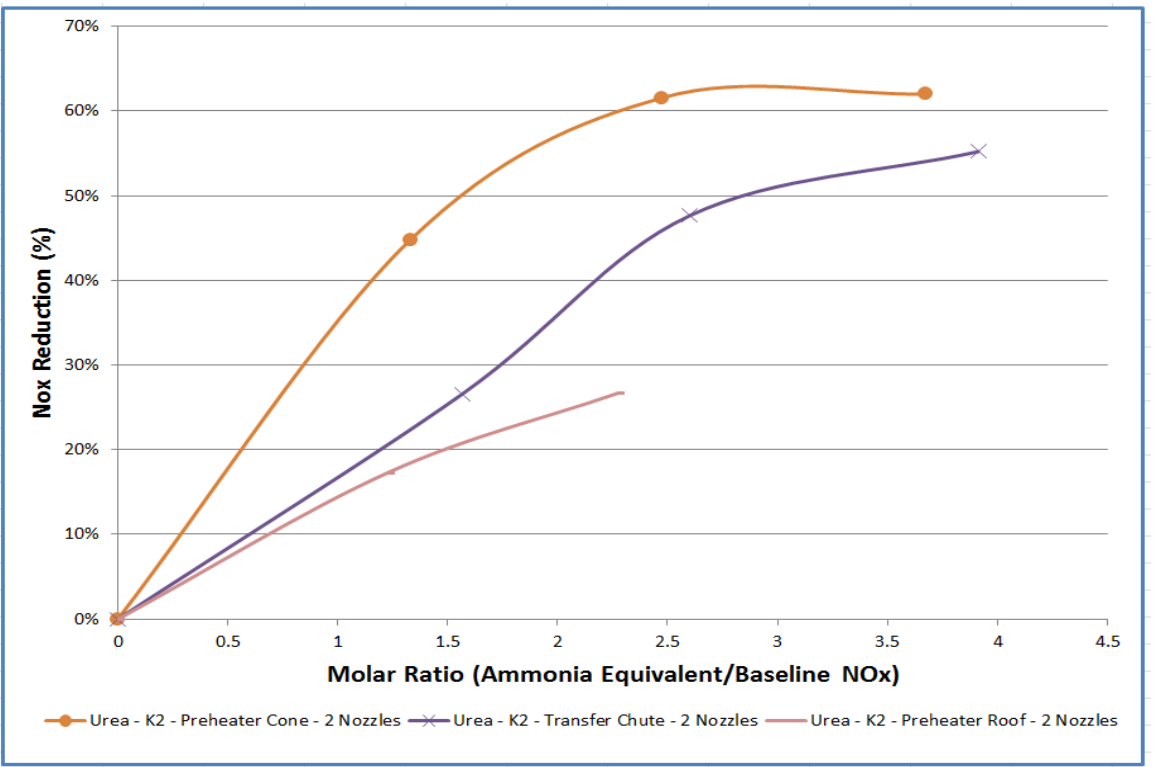

Figure 8: Comparison of Injection Locations for Urea Reagent

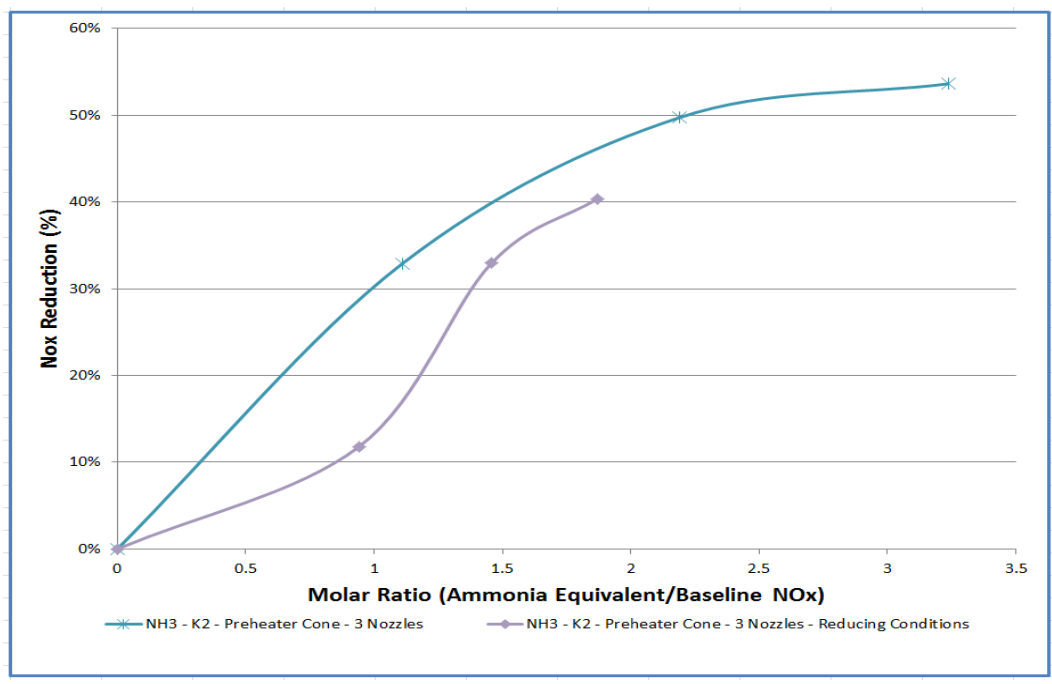

Figure 9: Effect of Reducing Conditions on SNCR Effectiveness using Ammonia Reagent

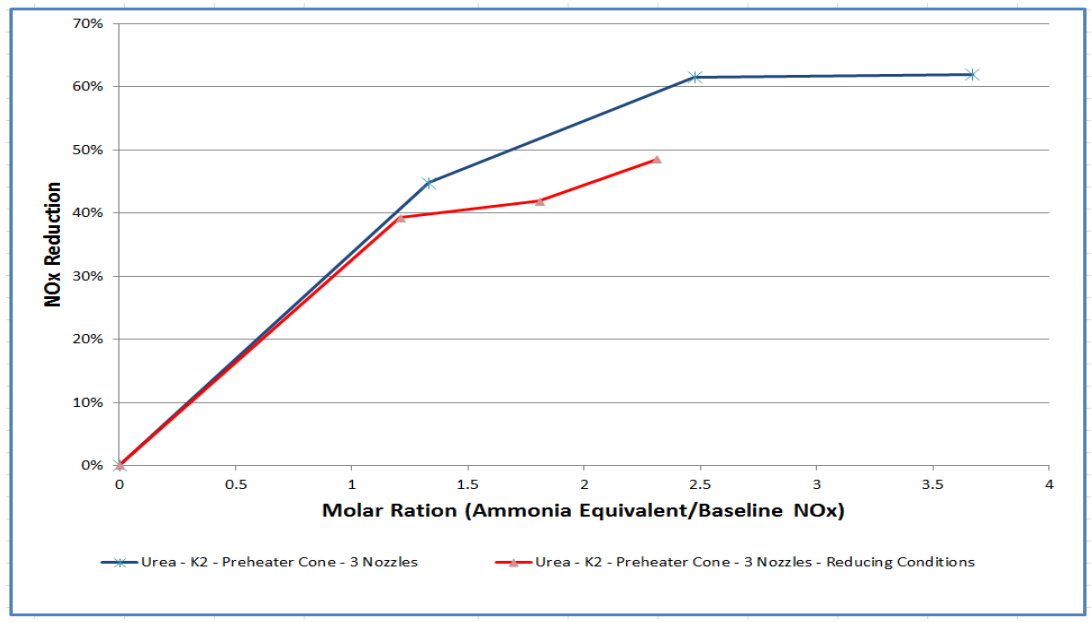

Figure 10: Effect of Reducing Conditions on SNCR Effectiveness using Urea Reagent 


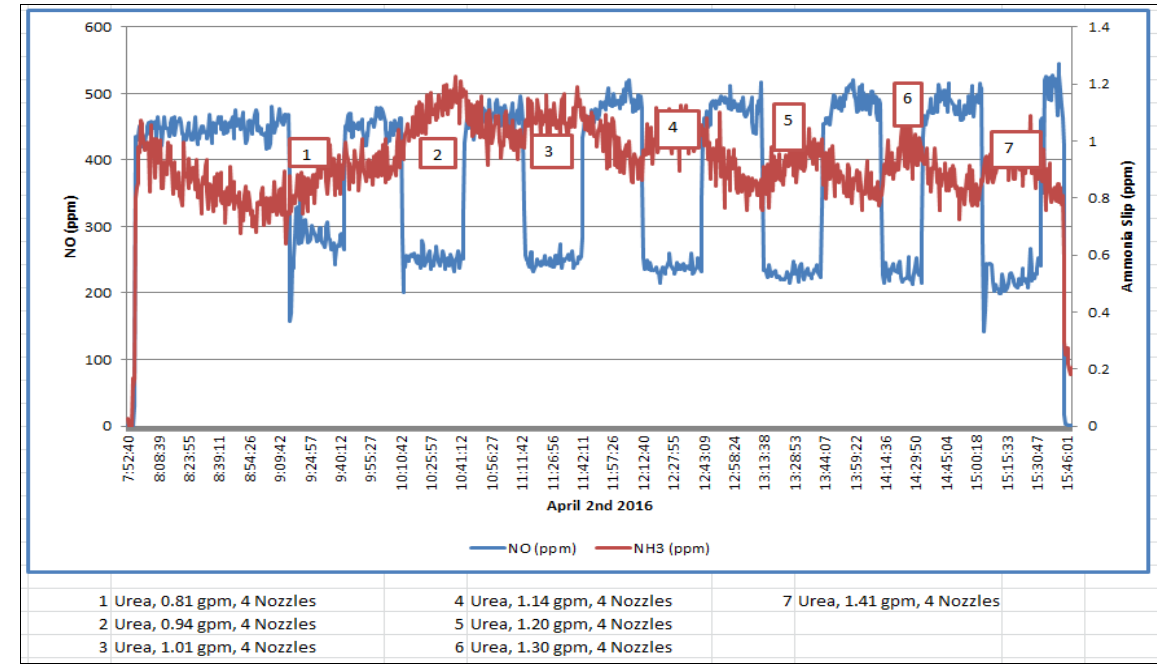

Figure 11: Ammonia Slip measurements at the baghouse inlet

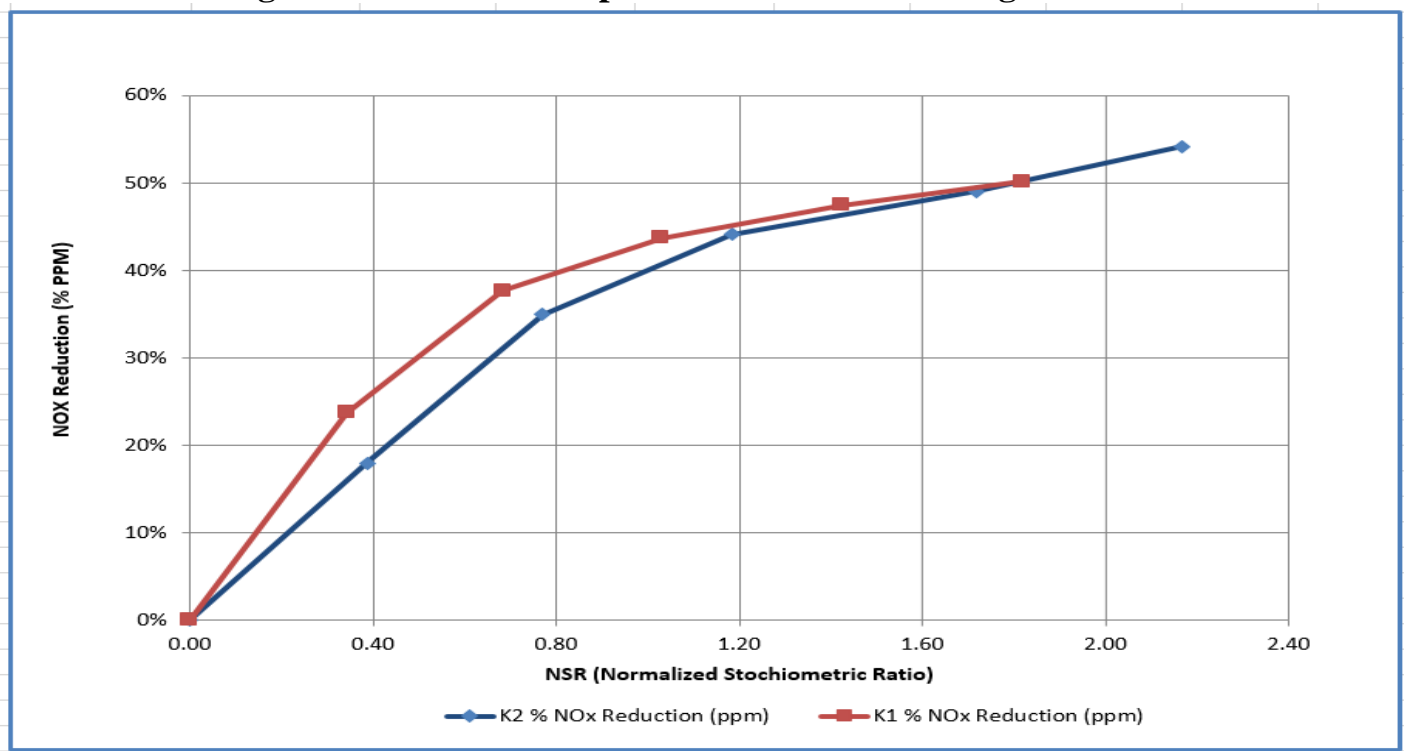

Figure 12: NOx reduction efficiency for both Kiln 1 and Kiln 2

The temperature in the preheater cone for lime preheater kilns ranges from $1800-2100^{\circ} \mathrm{F}$. The higher efficiency found in this region corresponds to the possibility of the optimum temperature for the reduction of NOx being in this region. The NOx reduction reaction occurs within a specific temperature range which is dependent on reagent utilized where adequate heat is available to drive the reaction. For ammonia, the optimum temperature is from $870-1100^{\circ} \mathrm{C}(1,600$ $\left.2,000^{\circ} \mathrm{F}\right)$ while for urea, the optimum temperature range is between $900-1150^{\circ} \mathrm{C}\left(1,650-2,100^{\circ} \mathrm{F}\right)($ United States Environmental Protection Agency, 2002). For each of these locations, urea reagent had better NOx reduction efficiency. It is possible that due to higher temperatures at the transfer chute, some of the reagents may have oxidized to form additional NOx.

The residence time of the flue gas at the preheater cone is also expected to be higher than the transfer chute since the cross-sectional area is bigger and hence lower gas velocity. Residence time is the amount of time the reactants are present within the chemical reactor. Increasing the residence time available for mass transfer and chemical reactions generally increases the NOx removal.

However, injection on the preheater roof was not successful for both reagents. The injection was stopped after ammonia slip was detected at the baghouse inlet. Two reasons could be attributed to this. First, the temperature in this location could have been low to sustain the expected ionization reaction of the reagents. Measured temperature in this region was $1600^{\circ} \mathrm{F}$. At lower temperatures the reaction kinetics is slow and ammonia passes through as ammonia slip. Secondly, the preheater roof is very wide compared to the transfer chute and the preheater cone and therefore it may not have been possible to have good mixing between the reagents and the flue gas. 


\section{Burning Conditions}

To simulate reducing conditions (combustion air less than stochiometric), oxygen $\left(\mathrm{O}_{2}\right)$ at the kiln exit was lowered to nearly zero which increased the kiln exit carbon monoxide (CO) to more than $5000 \mathrm{ppm}$. Normally kiln exit $\mathrm{O}_{2}$ is $1 \%$ with CO of less than $1000 \mathrm{ppm}$. It was noted that SNCR system would not perform as well in excessive reducing conditions. The presence of $\mathrm{CO}$ was noted to reduce NOx reduction by about $10 \%$ compared to running under oxidized conditions. The same observation was made by Pohl etal (Pohl, Yang, Sowa, \& Dill) who noted that increased concentrations of $\mathrm{CO}$ were found to reduce the NOx reduction and create a peak in the NH3 slip.

From Equation 1 and 2, it is seen that the reduction of 2 moles of nitrogen oxide (NO) by either urea or ammonia requires 0.5 moles of oxygen. Absence of oxygen therefore would either slow the reaction or the reaction may not be fully completed and that is why the overall NOx reduction efficiency is reduced.

At constant kiln exit $\mathrm{O}_{2}$ and $\mathrm{CO}$, there was a slight increase in $\mathrm{CO}$ of between 15-20 ppm during the urea injection. This would be expected as the urea molecule $(\mathrm{CO}(\mathrm{NH} 2) 2)$ breaks down, the $\mathrm{CO}$ in the molecule would be released and some of the $\mathrm{CO}$ may escape unconverted to $\mathrm{CO}_{2}$ due to lack of enough energy and/or oxygen to support the reaction kinetics

\section{Ammonia Slip}

Ammonia slip refers to the portion of the injected reagent which is unreacted and remains in the flue gas. Ammonia in the flue gas stream has several negative impacts. Ammonia has a detectable odor at levels of $5 \mathrm{ppm}$ or greater and poses a health concern at levels of $25 \mathrm{ppm}$ or greater (United States Environmental Protection Agency, 2002). It can cause a stack plume visibility problem by the formation of ammonium chlorides which occur when burning fuels containing chlorine compounds or ammonium bisulfate and ammonium sulfate form when burning sulfur-containing fuels. Ammonia-sulfur salts can plug, foul, and corrode downstream equipment such as ducts, baghouses and fans.

A continuous gas sampling system (MKS MultiGas 2030 FTIR) was set-up at a baghouse inlet to monitor ammonia slip levels before the potential for scrubbing of ammonia in the baghouse. As shown in Figure 11, no significant slip was noted at the baghouse inlet. The baghouse is located between the preheater and the stack.

\section{Effectiveness of SNCR in a lime Kiln}

After the best location was identified as the preheater cone, number of nozzles identified as four and urea chosen as the better reagent for final SNCR system in a lime kiln based on higher efficiency obtained compared to ammonia, another run was conducted on both kilns. This testing involved varying flow rates from 0-1.2 gpm at 0.2 increments. This testing was run for 8 hours a day for 4 days for each kiln. For each increment, a baseline was chosen as 2 hours prior to injection, the injection was then done for two hours before the system was left stabilize for another 2 hours before another injection was done.

The injection stopped at $1.2 \mathrm{gpm}$ after it was noted that further increase of injection rate did not yield further reduction in NOx. Figure 12 shows the NOx reduction results for both Kiln 1 and Kiln 2.

The results prove that SNCR system can work in a preheater lime kiln and at least $50 \%$ of NOx reduction can be achieved. It was also noted that increasing the injection rate would increase NOx reduction up to a point (in this case NSR of 1.6) after which further reduction in NOx would not proportionally reduce NOx. It is recommended to identify this plateau point in the actual SNCR installations so that the operation can be able to set limits to avoid wastage of the reagent hence saving on the cost of operation.

\section{Conclusions and Recommendation}

In this trial, it has been proven that Selective Non-Catalytic Reduction (SNCR) is effective and can be used to control nitrogen dioxide (NOx) emissions in preheater lime kilns. At least 50-60\% of NOx reduction can be achieved at reasonable cost and effectiveness. No side effects were noted during the trial. Change in specific heat consumption was negligible and no loss in production was noted.

With at least 50\% NOx reduction, this gives SNCR as the best available technology for NOx emission control in lime kilns. Other known method which can be applicable in lime kilns include flame cooling (20-30\% NOx reduction), Low NOx Burner (0-30\% NOx reduction) and Mid Kiln Air Injection (10-40\% NOx reduction) (Lafarge Cement- Techinical Agenda, 2005). Flame cooling is known to increase specific heat consumption and also make the kiln unstable which leads to loss of production. There is no guarantee that Low NOx burners would have an effect in NOx while mid kiln air injection is known to increase carbon monoxide emissions at the kiln exit especially for kilns that are induced draft fan limited. Mid kiln air injection would increase specific heat consumption as injected cold air mid kiln replaces the hot secondary air from the cooler. The product is also likely to exit the cooler hotter when using mid kiln air injection which would risk downstream equipment. 
Both Urea and Ammonia can be used as reagents in the SNCR system, but urea was found to be more effective. This is believed to be due to the higher temperature at the injection points, a temperature range where urea is known to be more effective than urea. Location of the injection point was also found to be an important factor. For the preheater lime kilns, the best injection point was found at the preheater cone though injection at the transfer chute would also work but at lower NOx reduction efficiency. The preheater cone was attributed to having a favorable temperature profile for the SNCR reaction. Increasing the number of injectors increases the NOx reduction efficiency and this is attributed to enhancing the reagent distribution in the gas stream leading to higher reaction surface areas.

Ammonia slip was found to be negligible as long as injection is done at the preheater cone or the transfer chute. Injection at the preheater roof is not recommended. When running SNCR, it is recommended to run the kiln in oxidized conditions. Presence of carbon dioxide was found to lower SNCR effectiveness by about $10 \%$. Selective Non-Catalytic Reduction should not only be considered as one of the best available techniques for NOx reduction in preheater lime kilns but also the best choice in terms of effectiveness.

Biography: Gideon Siringi, PhD, PE, is currently a Senior Process Engineer for Lhoist North America, a leading manufacturer of Lime and Limestone in the world. Gideon graduated with a Ph.D. degree in Materials Science and Engineering from The University of Texas at Arlington. He received his B.S. and M.S. in Chemical Engineering from Moi University and Lamar University respectively. Gideon previously worked as a Process Engineer for Texas Industries- Midlothian Cement Plant and Lafarge Cement (Bamburi Plant), Mombasa, Kenya. Dr. Siringi's research interests are in the development of sustainable concrete and the use of recyclable materials in concrete, renewable energy, process modification for pollution prevention and improved energy efficiency.

\section{References}

Clean Air Technology Center (MD-12). (1999). Nitrogen Oxides (NOx), Why and How They Are Controlled. Office of Air Quality Planning and Standards. Research Triangle Park, North Carolina: U.S. Environmental Protection Agency.

EPRI. (2004). SNCR Guidelines Update. Palo Alto, CA: Electric Power Research Institute, Inc.

Lafarge Cement- Techinical Agenda. (2005). NOx reduction techniques. France: Direction des Performances Cimentières.

Pohl, J. H., Yang, S.-C., Sowa, W. A., \& Dill, J. W. (n.d.). LIMITS TO NOx REDUCTION BY NH3 INJECTION. Irvine. California: University of California .

Sun, W. H. (2005). Selective Non-Catalytic Reduction: Overview. WPCA/Duke NOx Seminar. Charlotte, NC.

United States Environmental Protection Agency. (2002). EPA AIR POLLUTION CONTROL COST MANUAL. Research Triangle Park, North Carolina: Office of Air Quality Planning and Standards. 